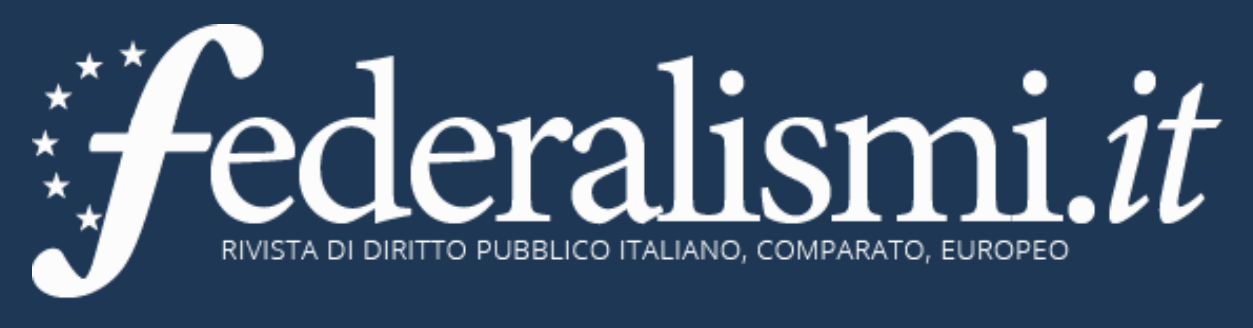

17 APRILE 2019

\title{
The open Internet vs. net neutrality and the free Internet
}




\title{
The open Internet vs. net neutrality and the free Internet ${ }^{*}$
}

\author{
by Paolo Damiani \\ Assistant Professor of Constitutional Law \\ University of Udine
}

\begin{abstract}
It]: Le locuzioni "Net neutrality", "free Internet" e "open Internet" non sono sinonime ma altrettante diverse declinazioni del principio di non discriminazione del traffico Internet. Dopo averne illustrato in modo dettagliato le caratteristiche, lo studio individua quale fra queste tre interpretazioni del principio in esame è stata adottata dal 2015 Open Internet Order e dal 2018 Restoring Internet Freedom Order. Mentre il primo, contrariamente alla sua intitolazione e forse anche all'intenzione del suo artefice, ha optato per la tutela della Net Neutrality, il secondo ha salvaguardato la free Internet. Pur così distanti se non addirittura contrastanti, queste due scelte interpretative condividono la medesima origine che lo studio individua nella cattura del regolatore $\mathrm{o}$, più precisamente, nella preoccupante permeabilità della Federal Communications Commission ai condizionamenti del populismo, della politica e dell'economia. Più adatta alle peculiarità del mercato U.S.A. del servizio di accesso in banda larga a Internet, caratterizzato soprattutto dalla mancanza di concorrenza tra i broadband providers, sarebbe stata la scelta di tutelare la open Internet.
\end{abstract}

Table of Contents. 1. Introduction. 2. Net neutrality, the free Internet, and the open Internet. 3. The dual protective nature of the open Internet. 4. The pragmatic and rational nature of an open Internet. 5. The FCC Orders. 6. The 2015 Open Internet Order. 6.1. The Internet-traffic nondiscrimination principle under the 2015 Open Internet Order. 7. The Internet-traffic nondiscrimination principle under the 2018 Restoring Internet Freedom Order. 8. The protection of freedom from Internet traffic discrimination in the 2018 Restoring Internet Freedom Order 8.1. The ineffective protection afforded under the 2018 order. 9. What might explain the FCC's policymaking, and why it is ill-suited to the North American BIAS market. 10. Conclusion.

\section{Introduction}

The terms net neutrality, free Internet, and open Internet are not synonymous but rather point to three different ways of construing the principle of nondiscrimination in the treatment of Internet traffic.

Net neutrality protects freedom from discrimination among types or sources of Internet traffic, without regard to any competing interests or countervailing considerations. On this understanding of the nondiscrimination principle, discriminatory practices are inherently harmful, and as such must be prohibited across the board, no matter what.

The free Internet only prohibits anticompetitive discrimination.

\footnotetext{
* Peer reviewed.
} 
And, finally, the open Internet protects two competing freedoms: freedom from discriminatory practices and the freedom to engage in such practices.

This study aims to (1) closely examine each of these three understandings of the nondiscrimination principle; (2) identify which of them best describes the policy adopted by the U.S. Federal Communications Commission (FCC); (3) explain the FCC's decision-making by pointing out the forces that feed into it; and, finally, (4) assess the agency's policies in the context of the Broadband Internet Access Service (BIAS) market in which they are implemented, arguing that there is a disconnect between those policies and that market.

\section{Net neutrality, the free Internet, and the open Internet}

Net neutrality aspires to a perfectly neutral network and envisages a legal prohibition on any discrimination by broadband providers, with the single exception of reasonable network management. ${ }^{1}$ On a free Internet model, by contrast, the law should only prohibit anticompetitive discrimination that hinders the market's proper functioning. If interests other than competition are harmed by the discriminatory practices of broadband providers, and these interests warrant protection, it is up to the market, and not to the law, to see to it that they are protected.

The open Internet, for its part, can in some respects be understood as staking out a position halfway between net neutrality and the free Internet: unlike the former it does not ban all discrimination, and unlike the latter it does not only prohibit anticompetitive discrimination.

This is an approach reminiscent of Popper's concept of an open society. ${ }^{2}$ For, like in the open society, where actions are not predetermined but are the result of its members' free and autonomous choices, so in the open Internet decisions about Internet-traffic management are, by and large, left to the broadband providers' free and autonomous choice, and should not—as the proponents of net neutrality would want-be constrained by a set of obligations and prohibitions imposed on the same providers. More briefly stated, in the open society and the open Internet alike, outcomes are determined not by a command structure but by the free interchange that takes place among individuals acting under an agreed set of rules.

The open Internet thus envisions an area of legally protected economic freedom within which broadband providers can discriminate among sources and types of Internet traffic. Unlike what the free internet

\footnotetext{
${ }^{1}$ Reasonable network management is a noncommercial practice aimed at ensuring network security and integrity by blocking unwanted traffic from end users and resolving or mitigating network congestion.

${ }^{2}$ K. R. POPPER, The Open Society and Its Enemies, The Spell of Plato, vol. I, London, 1947, p. 152.
} 
envisions, however, the boundaries delimiting this area do not result solely from a prohibition on anticompetitive discriminatory practices: further restrictions are called for in the open Internet.

\section{The dual protective nature of the open Internet}

As noted in the Introduction, the open Internet protects two competing freedoms, one negative and the other positive: (a) the freedom of end users and edge providers from Internet-traffic discrimination, and (b) the freedom of broadband providers to discriminate among different sources and types of Internet traffic.

In order to resolve the conflict between these two freedoms, the open Internet strikes a balance between them. This has yielded three solutions to the conflict, each consisting in a different balancing between the two freedoms. Two of the solutions are at polar opposites: in one, (negative) freedom A is accorded the greatest protection, correlating with the least protection for (positive) freedom B; in the other, the scales are tipped in exactly the opposite direction. In the third solution, finally, the two freedoms are more or less evenly balanced.

Before going into these three solutions in detail, we should bear in mind that Internet-traffic discrimination can be either technical or commercial, and each can be either negative or positive.

(1) The minimum protection of (negative) freedom A, correlating with the maximum protection of (positive) freedom B, prohibits all negative discrimination, whether technical or commercial. Negative discrimination is technical when it denies access to a best-effort service on the Internet (blocking) or when the service delivered falls short of that standard (throttling); it is instead commercial when it forces edge providers to pay broadband providers a fee to avoid their content and applications from being blocked or slowed down.

The prohibition on negative discrimination can equally be expressed in the form of a general prohibition (the no-disadvantage rule) or in the form of three particular prohibitions (the no-blocking rule, the nothrottling rule, and the no-charging edge providers rule).

Under this balancing solution, then, broadband providers can engage in any kind of positive discrimination (i.e., preferential treatment), be it technical or commercial. This regulatory solution provides the weakest protection of (negative) freedom A (freedom from discrimination) and the strongest protection for (positive) freedom B (the freedom to discriminate).

(2) In the regulatory balancing solution that accords roughly the same protection to freedoms A and B alike, these freedoms are restricted not only by a prohibition on negative discrimination but also by a certain number of prohibitions relating to individual and specific preferential treatment (positive discrimination). However, such preferential treatment cannot come under a general prohibition. A 
prohibition of this kind, if coupled with a prohibition on negative discrimination, would be tantamount to depriving broadband providers of all economic freedom.

This means that lawmakers cannot implement a general ban on the provision of services of higher quality than what the best effort calls for, but they can, for example, prohibit paid prioritization; they cannot implement a general ban on preferential business practices, but they can, for example, prohibit sponsored data; and so on.

Furthermore, there cannot be too many prohibitions. Otherwise the freedom to discriminate among different sources and types of Internet traffic would in fact be reduced to zero or would receive less protection than what is accorded to freedom from discrimination.

While that degree of protection would not be consistent with balancing solution 2, it is consistent with the third one, to which we can now turn.

(3) In the third and last regulatory solution, (negative) freedom A is accorded the strongest protection, and (positive) freedom B the weakest.

To achieve this result, lawmakers will not only prohibit negative discrimination but will also put in place a great many prohibitions against positive discrimination, or they will prohibit unreasonable discrimination.

This last prohibition calls for great caution in its formulation. Lawmakers entrust regulators with the power to decide, on a case-by-case basis, which forms of discrimination are reasonable, and thus lawful, and which are unreasonable, and thus unlawful. It is thus necessary for the lawmaker to limit as far as possible the discretion granted to the regulator. Otherwise legal certainty would cease to exist, and with it the freedom of broadband providers to discriminate in their treatment of Internet traffic.

In whatever way the prohibition on unreasonable discrimination is formulated, its effect will be to secure the greatest protection for (negative) freedom from discrimination and, conversely, the least protection for the (positive) freedom to discriminate. The simple and obvious reason for this effect is that discrimination can be considered inherently unreasonable: regulators can therefore prohibit it as such even if it is not subject to any explicit prohibition.

The first balancing solution deems (negative) freedom from discrimination more important than the (positive) freedom to discriminate. The third solution takes the exact opposite tack. The second solution ascribes the same weight to the two freedoms.

What lawmakers will decide, in choosing one solution over another, will depend on which of the two freedoms they regard as more important, as well as on the context-historical, economic, technological, social, cultural, political, etc.- -in which the choice is made and in which its intended effect is to take its course. 
In conclusion, none of the three regulatory solutions just outlined is inherently superior to any of the others in protecting an open Internet, save for the fact that legal certainty may be undermined by a prohibition on unreasonable discrimination.

\section{The pragmatic and rational nature of an open Internet}

The differential treatment the open Internet reserves for negative and positive discrimination can be explained in two ways.

On the one hand, there is the previously mentioned point about regulatory effect: if on top of the prohibition against negative discrimination, the legislator were to enact a similar one on positive discrimination, this would end up effectively depriving broadband providers of their economic freedom. That would run counter to the dual protection on which the open Internet is predicated, meaning its commitment to protect the (negative) freedom of end users and edge providers from discrimination and the (positive) freedom of broadband providers to discriminate in their management of Internet traffic. On the other hand, there is an IT/engineering factor that needs to be taken into account. The best-effort service is the basic communications service that online applications use to function on the Internet. This means that whether a broadband provider denies access to a best-effort service (blocking) or delivers any service below that standard (throttling), the outcome is the same: either practice is equivalent to preventing the use of the Internet. The severity of the damage these discriminatory practices cause to users and suppliers of the application subject to discrimination justifies an absolute prohibition.

Positive discrimination is the preferential treatment that consists in favouring one or more applications or classes of applications: this can be done by way of commercial practices or by delivering a quality of service superior to the best-effort standard. Unlike blocking or throttling, then, positive discrimination never involves preventing the use of the Internet by one or more applications or classes of applications. Moreover, the effects of positive discrimination are sometimes socially desirable, and the nature of the open Internet, at once pragmatic and rational, allows them to be preserved. By these two attributespragmatic and rational - is meant here the idea that on an open Internet understanding of the principle of nondiscrimination among different types and sources of Internet traffic, this principle needs to be viewed in the context of its application, thereby taking into account the advantages and disadvantages of any discriminatory practice in that context. On this view, in other words, nondiscrimination is approached not from an ideological stance but on the basis of a pragmatic attitude that asks what is most effective (i.e., rational) in view of the aims sought to be achieved and the criteria to be met. And only in context can such a determination be made. 
Let us take paid prioritization as an example. As is known, those who argue that this practice should be prohibited proceed from the incontrovertible premise that since Internet innovation «has come primarily from the "edge" or "end" of the network through application competition», ${ }^{3}$ the growth of the Internet is by and large a result of the innovation brought by online applications.

This means that the Internet simply could not have grown without the success of online applications. That being the case, discrimination by means such as paid prioritization, which hinders or prevents innovation in online applications, works contrary to the general interest in enabling the Internet to expand as quickly and as widely and as possible. Hence the conclusion that such practices need to be prohibited. If the premise of the argument is irrefutable, however, the same cannot be said of its conclusion. For it is necessary to take into account the different contexts in which paid prioritization can be practised, considering in particular the engineering and economic differences between fixed and mobile broadband services.

Mobile services «have relatively low bandwidths» ${ }^{4}$ compared to fixed services, and yet, paradoxically, they are expected to be the first to have to meet the increase in bandwidth demand in the coming years. It has been estimated, for example, that in the United States «consumer Internet video traffic will be $81 \%$ of consumer Internet traffic in 2021, up from 79\% in 2016», ${ }^{5}$ and that «video will be $80 \%$ of the United States's mobile data traffic in 2021, compared to 64\% at the end of 2016». ${ }^{6}$ A further and perhaps more telling example is that of self-driving cars. It has been estimated that «each autonomous vehicle will be

\footnotetext{
${ }^{3}$ L. LESSIG - C. WENDELL - E. M. CARLSMITH, Testimony of Lawrence Lessig C. Wendell and Edith M. Carlsmith Professor of Law Stanford Law School Senate Committee on Commerce, Science and Transportation Hearing on "Network Neutrality" February 7, 2006, pp. 3-4; https://cyberlaw.stanford.edu/files/publication/files/lessig-020706.pdf. The authors give some examples: «indeed, if you consider some of the most important innovations in this history of the Internet—from the development of the World Wide Web by a Swiss researcher at CERN, to the first peer-topeer instant messaging chat service, ICQ, developed by a young Israeli, to the first web based (or HTML-based) email, HoTMaiL, developed by an Indian immigrant - these are all innovations by kids of non-Americans: outsiders to the network owners». Similarly, M.A. LEMLEY - L. LESSIG, The End of End-to-End: Preserving the Architecture of the Internet in the Broadband Era, in U.C. Berkeley Public Law and Legal Theory, Research Paper No. 36, 2000, p. 8, http://papers.ssrn.com/paper.taf?abstract id=247737. According to S.P. CRAWFORD, Network Rules, in Benjamin N. Cardozo School of Law Jacob Burns Institute for Advanced Legal Studies, Working Paper No. 159, 2006, p. 21, http://ssrn.comb /abstract=885583, «the telcos and cablecos have not created successful online businesses or any notable innovations associated with online life». Indeed, it is clear that «when new applications, content, and services are developed by edge providers, we use the Internet more, leading broadband providers to increase the speed and capacity of their networks, sparking the development of more and better applications, content, and services, faster networks, and so on (Professors letter to FTC, http://www.pijip.org/wpcontent/uploads/2015/01/Net-Neutrality-Prof-Letter-01292015.pdf).

${ }^{4}$ J. F. KUROSE - K. W. ROSS, Computer Networking: A Top-Down Approach, $6^{\text {th }}$ ed., Boston, 2013, p. 577.

${ }_{5}$ CISCO, United States - 2021 Forecast Highlights, https://www.cisco.com/c/dam/m/en_us/solutions/serviceprovider/vni-forecast highlights/pdf/United_States_2021_Forecast_Highlights.pdf.

${ }^{6}$ Idem, United States - Mobile Higblights, https://www.cisco.com/c/dam/m/en_us/solutions/service-provider/vniforecast-highlights/pdf/United_States_Mobile_Highlights.pdf.
} 
generating approximately 4,000 GB_or 4 terabytes_of data a day». ${ }^{7}$ Most of this huge data traffic «will be carried by wireless networks». ${ }^{8}$

Before banning paid prioritization in mobile services, any good regulator should thus balance the needs of sustainability and innovation in the mobile-service infrastructure against those of innovation in online applications. In this process the former needs could end up outweighing the latter, in which case paid prioritization would have to be considered socially desirable, making it possible to pass on to providers of "bandwidth hungry" applications some of the costs that broadband providers incur for expanding the LTE network and, especially, for building the future $5 \mathrm{G}$ network.

\section{The FCC Orders}

The idea that there should be no discrimination among different sources or types of Internet trafficwhat I am calling the Internet-traffic nondiscrimination principle-was largely ignored at the dawn of the Internet. The term "network neutrality" first appeared in an article that Tim Wu published in 2003," around which time it became a topic of discussion among a coterie of professionals. Only later did this become a hotly contested idea-first among experts in telecommunications law, ${ }^{10}$ and now in the political

7 B. KRZANICH, Data Is the New Oil in the Future of Automated Driving, https://newsroom.intel.com/editorials/krzanich-the-future-of-automated-driving/: «every autonomous car will generate the data equivalent of almost 3,000 people. Extrapolate this further and think about how many cars are on the road. Let's estimate just 1 million autonomous cars worldwide- that means automated driving will be representative of the data of 3 billion people».

8 Statement of Commissioner Michael O'Riellly, p. 530.

9 T. WU, Network Neutrality, Broadband Discrimination, in Journal of Telecommunications and High Technology Law, 2003, vol. 2, p. 141, http://papers.ssrn.com/sol3/papers.cfm?abstract id=388863\#\#.

The expression is relatively recent but «the idea behind the term has been a central focus of network theorists since the early 1980s. "Network Neutrality" builds upon a fundamental recognition about the relationship between a certain network design (what network architects Jerome Saltzer, David Clark, and David Reed called the "end-toend" principle) and economic innovation» (L. LESSIG - C. WENDELL - E. M. CARLSMITH, Hearing before the Committee on Commerce, Science, and Transportation United States Senate, One Hundred Tenth Congress, Second Session april 22, 2008; Prepared Statement of Lawrence Lessig, C. Wendell and Edith M. Carlsmith Professor of Law, Stanford Law School, 2008, p. 52, http://www.gpo.gov/fdsys/pkg/CHRG-110shrg74893/html/CHRG-110shrg74893.htm”).

${ }^{10}$ Examples are as follows: C.S. YOO, Is There a Role for Common Carriage in an Internet-Based World? in Houston Law Review, 2013, vol. 51, p. 545, http://ssrn.com/abstract=2370068; Idem, Network Neutrality after Comcast: Toward a Case-by-Case Approach to Reasonable Network Management, in New Directions in Communications Policy, 2009, http://ssrn.com/abstract=1511892; Idem, Network Neutrality and the Economics of Congestion, in Georgetown Law Journal, 2006, vol. 94, p. 1947, http://ssrn.com/abstract=825669; Idem, Beyond Network Neutrality, in Harvard Journal of Law \& Technology, 2005, http://papers.ssrn.com/sol3/papers.cfm?abstract id=742404"; T. WU - C. YOO, Keeping the Internet Neutral?: Tim $W u$ and Christopher Yoo Debate, in Federal Communications Law Journal, 2007, http://www.repository.law.indiana.edu/fcli/vol59/iss3/6; T. WU - L. LESSIG, Re: Ex Parte Submission in CS Docket No. 02-52, 2002, p. 2, http://www.timwu.org/wu lessig fcc.pdf; B. VAN SCHEWICK, Network. Neutrality and Quality of Service: What a Non-Discrimination Rule Should Look Like, in Stanford Law Review, 2015, vol. 67, pp. 9899; Idem, Towards an Economic Framework. for Network Neutrality Regulation, in J. on Telecomm. \& High Tech., 2007, p. 328, http://ssrn.com/abstract=812991; B.M. FRISCHMANN - B. VAN SCHEWICK, Network Neutrality and the Economics of an Information Superbigbway: A Reply to Professor Yoo, in Jurimetrics J., 2007, p. 47, 
arena, where the principle has become divisive and forms the subject of several orders by the Federal Communications Commission (FCC). ${ }^{11}$

http://papers.ssrn.com/sol3/papers.cfm?abstract id=1014691; D. A. HASS, The Never-Was-Neutral Net and Why Informed End Users Can End the Net Neutrality Debates, in Berkely Techology Law Journal, 2007, http://scholarship.law.berkeley.edu/cgi/viewcontent.cgi?article=1717\&context=btli; P. GANLEY - B. ALLGROVE, Net neutrality: A User's Guide, in Computer, Law \& Security Report, 2006, vol. 22, http://papers.ssrn.com/sol3/papers.cfm?abstract id=925693; A. THIERER - M. WENDY, The Constructive Alternative to Net Neutrality Regulation and Title II Reclassification Wars, in Progress on Point, n. 9/2010, vol. 17, p. 1, http://ssrn.com/abstract=1614884; P. WEISER, The Future of Internet Regulation, in U. of Colorado Law Legal Studies Research Paper, 2009, p. 529, http://ssrn.com/abstract=1344757; A. THIERER, Are "Dumb Pipe" Mandates Smart Public Policy? Vertical Integration, Net neutrality, and the Network Layers Model, in J. On Telecomm. \& High Tech. L., 2005, p. 275, http://www.jthtl.org/content/articles/V3I2/JTHTLv3i2 Thierer.PDF; T. WU, The Broadband Debate: $A$ User's Guide, in Journal of Telecommunications and High Technology Law, 2004, vol. 3, p. 69, http://ssrn.com/abstract=557330; A. NEILL, How the FCC Can Preserve the Open Internet \& Net Neutrality through Title II Reclassification: The Case for Reclassifying Broadband Internet Access under Title II, and Adopting Rules That Protect the Open Internet, http://papers.ssm.com/sol3/papers.cfm?abstract id=2550431, 2014; H. GUO - S. BANDYOPADHYAY - A. LIM-YU-CHEN BEN YANG - H. KENNETH CHENG, Effects of Competition among Internet Service Providers and Content Providers on the Net Neutrality Debate, 2015, http://papers.ssrn.com/sol3/papers.cfm?abstract id=2529693; O. SYLVAIN, Network. Equality, in Hastings Law Journal, 2016, p. 443, http://papers.ssrn.com/sol3/papers.cfm?abstract id=2588053; R. FRIEDEN, Network Neutrality and Consumer Demand for "Better than Best Efforts" Traffic Management, 2015, http://papers.ssrn.com/sol3/papers.cfm?abstract id=2611689".

11 President Obama issued a statement on net neutrality, calling for «the strongest possible rules to protect net neutrality» (http://www.whitehouse.gov/net-neutrality\#section-read-the-presidents-statement). Against this statement the Republican members of Congress sent a letter to the FCC's chairman (http://www.coats.senate.gov/newsroom/press/release/coats-obamas-net-neutrality-regulations-would-stifleinnovation). Contrary to that, Republican Henry A. Waxman sent a letter to the FCC calling for a «No Paid Prioritization Rule» (https://apps.fcc.gov/edocs public/attachmatch/DOC-329779A1.pdf). President Obama's statement ignited a debate on net neutrality, with the chairman of the FCC issuing a statement (FCC Chairman Tom Wheeler's Statement on President Barack Obama's Statement on the open internet: http://www.fcc.gov/document/chairman-wheelers-stmt-president-obamas-stmt-open-internet) that largely supports President Obama's statement. Contrary to that, Commissioners Ajit Pai and Michael O'Rielly issued several statements against President Obama's statement: Statement of FCC Commissioner Ajit Pai on President Obama's Plan to Regulate the Internet, http://www.fcc.gov/document/comm-pais-stmt-president-obamas-plan-regulateinternet; Press Statement of FCC Commissioner Ajit Pai on President Obama's Plan to Regulate the Internet; http://www.fcc.gov/document/comm-pai-press-stmt-president-obamas-plan-regulate-internet; Statement of FCC Commissioner Ajit Pai on the Latest Evidence That Regulating the Internet Will Reduce Broadband Deployment and Competition; http://www.fcc.gov/document/comm-pai-stmt-latest-evidence-against-regulating-internet; What People Are Saying about President Obama's Plan to Regulate the Internet, http://www.fcc.gov/document/what-people-are-saying-aboutpresidents-plan-regulate-internet; The American People Oppose President Obama's Plan to Regulate the Internet and Support FCC Transparency; http://transition.fcc.gov/Daily Releases/Daily Business/2015/db0220/DOC-332151A1.pdf; Statement of Commissioner Michael O'Rielly on Internet regulation and fauxbearance; $\mathrm{http}$ ://www.fcc.gov/document/oriellystatement-internet-regulation-and-fauxbearance; Remarks of FCC Commissioner Michael O'Rielly at The Free State Foundation's Policy Seminar: "Thinking the Unthinkable: Imposing the Utility Model" on Internet Providers"; http://www.fcc.gov/document/commissioner-oriellys-remarks-free-state-foundation; Statement of FCC Commissioners Ajit Pai and Mike O’Rielly Requesting Public Release of Internet Regulation Plan and Temporary Delay of Vote; http://transition.fcc.gov/Daily_Releases/Daily_Business/2015/db0223/DOC-332168A1.pdf. 
It is on three occasions that the FCC has regulated the discriminatory treatment of Internet traffic: in 2010 (under the 2010 Open Internet Order), in 2015 (under the 2015 Open Internet Order), and in 2018 (under the 2018 Restoring Internet Freedom Order).

\section{The 2015 Open Internet Order}

After the 2010 Open Internet Order was in part vacated, the FCC issued the 2015 Open Internet Order. What follows is a quick summary of its contents.

The 2015 Order laid down three prohibitions on as many discriminatory practices, thereby introducing (a) a no-blocking rule, (b) a no-throttling rule, and (c) a no-paid-prioritization rule. It also introduced a residual ban on unreasonable discrimination, resulting in (d) the no-unreasonableinterference/disadvantage standard. ${ }^{12}$

(a) The no-blocking rule prohibited broadband providers from blocking particular content, legitimate applications, or services or particular classes of content, legitimate applications, or services, as well as from blocking any non-harmful device on the ground that it may compromise network integrity. ${ }^{13}$

(b) The no-throttling rule prohibited broadband providers from slowing down or degrading traffic for particular content, applications, or services or particular classes of content, applications, or services, as well as from slowing down or degrading legitimate traffic that uses a non-harmful device.

(c) The no-paid-prioritization rule prohibited «the management of a broadband provider's network to directly or indirectly favour some traffic over other traffic, including through the use of techniques such as traffic shaping, prioritization, resource reservation, or other forms of preferential traffic management, either (a) in exchange for consideration (monetary or otherwise) from a third party, or (b) to benefit an affiliated entity». ${ }^{14}$

\footnotetext{
12 The 2015 Order also introduced a reasonable network management exception, applying to all the rules just mentioned except the no-paid-prioritization rule. Reasonable network management was defined on the basis of the definition contained in the 2010 Open Internet Order, but «with slight modifications» (FCC, 2015 Open Internet Order, par. 215, p. 100). Among them was the important clarification that the exception did not include «commercial practices». As a result, the exception applied to the no-blocking rule, the no-throttling rule, and the nounreasonable interference/disadvantage standard, but not to the no-paid-prioritization rule, because «unlike conduct implicating the no-blocking, no-throttling, or no-unreasonable interference/disadvantage standard, paid prioritization is not a network management practice» (FCC, 2015 Open Internet Order, par. 217, p. 100). Moreover, the exception did not apply to any discrimination carried out for commercial purposes. Finally, the 2015 Order prohibited unreasonable discrimination in providing interconnection services.
}

${ }_{13}^{13}$ FCC, 2015 Open Internet Order, par. 112, p. 48.

${ }^{14}$ Idem, par. 125, p. 53. 
(d) The no-unreasonable-interference/disadvantage standard was a «general conduct rule», ${ }^{15}$ or «catch-all standard», ${ }^{16}$ that prohibited broadband providers from interfering with or unreasonably disadvantaging end users $(i)$ in their ability to choose a Broadband Internet Access Service (BIAS) or (ii) in view of the lawful content, services, applications, and devices they choose to use through such a service. The standard also prohibited broadband providers from interfering with or unreasonably disadvantaging edge providers in their ability to provide end users with lawful content, services, applications, and devices. ${ }^{17}$

\subsection{The Internet-traffic nondiscrimination principle under the 2015 Open Internet Order}

If we were to go just by the short title of the 2015 Open Internet Order («Protecting and Promoting the Open Internet»), we might be justified in thinking that in that document the principle requiring nondiscrimination in the management of Internet traffic is construed as an open Internet principle. A closer look at the actual substance of the document, however, would prove us wrong in drawing such a conclusion.

The broad scope and vagueness of the general conduct rule as a «catch-all standard» meant that the 2015 Open Internet Order effectively took away the freedom of broadband providers to discriminate in their management of Internet traffic.

As noted in Section 6, at point (d), the general conduct rule was intended by the FCC as a standard by which to distinguish reasonable from unreasonable discrimination. To this end the FCC drew up a list of seven factors, namely, (i) end-user control; (ii) application-agnostic practice; (iii) standard practice; (iv) competitive effects; (v) free expression; (vi) consumer protection; and (vii) effect on innovation, investment, or broadband deployment. But these factors did not help the certainty of law, and in fact may even have been harmful to it. This for three reasons.

First, the list of factors was overabundant.

Second, there is no hierarchy that the 2015 Open Internet Order established among the seven factors. As a result, it was not clear how the FCC was going to judge «a practice that is in line with some, but not all factors mentioned by the order». ${ }^{18}$

And, third, the list was «non-exhaustive». ${ }^{19}$

\footnotetext{
15 Statement of Chairman Tom Wheeler, p. 315.

${ }^{16}$ FCC, 2015 Open Internet Order, par. 21, p. 9.

${ }^{17}$ Idem, par. 21, p. 9.

18 B. VAN SCHEWICK, Network Neutrality and Quality of Service, cit., p. 122.

${ }^{19}$ FCC, 2015 Open Internet Order, par. 138, p. 61.
} 
The uncertainty was in no way mitigated by giving broadband providers the ability to seek advisory opinions from the FCC. Indeed, by definition, these opinions were «not binding on any party» ${ }^{20}$ and could thus at any time be disregarded by the FCC.

So glaring was the vagueness of the general conduct rule that it drew attacks not only from opponents of the 2015 Open Internet Order, ${ }^{21}$ but also from some of its staunchest and keenest supporters. ${ }^{22}$

It would not be rash to suppose that if the general conduct rule had been kept in force, broadband providers would have refrained not only from the three expressly prohibited discriminatory practices but also from any discrimination. Refraining from any form of discrimination, however, is precisely the behaviour that broadband providers are required to have under net neutrality.

In the 2015 Open Internet Order, therefore, the nondiscrimination principle is shaped into a net neutrality principle (however much not expressly so but "only" de facto) - an outcome that is nothing short of paradoxical for a measure that in its very title purports to protect and promote the open Internet.

\section{The Internet-traffic nondiscrimination principle under the 2018 Restoring Internet Freedom}

\section{Order}

The 2015 Open Internet Order was repealed by the 2018 Restoring Internet Freedom Order. The 2018 order entrusts to economic forces the task of protecting freedom from the discriminatory practices of broadband providers, and posits that «to the extent these economic forces fail in any particular situation, existing consumer protection and antitrust laws additionally protect consumers». ${ }^{23}$

According to the 2018 order, «these long-established and well-understood antitrust and consumer protection laws are well-suited to addressing any openness concerns ${ }^{24}$ (italics added). And if the discriminatory behaviour of broadband providers «cannot be described as anti-competitive, unfair, or deceptive- then the conduct should not be banned in the first places ${ }^{25}$ (italics added).

What clearly emerges from these remarks is that, in the 2018 order, the Internet-traffic nondiscrimination principle is emphatically not construed as an open Internet principle: discriminatory practices are prohibited only insofar as they run afoul of antitrust or consumer protection laws. Which in turn means

20 FCC, Enforcement Bureau, Open Internet Advisory Opinion Procedures, 2015, p. 4, https://apps.fcc.gov/edocs public/attachmatch/DA-15-692A1.pdf.

21 Dissenting Statement of Commissioner Ajit Pai, p. 323.

22 USTA v. FCC, Brief of Amici Curiae Electronic Frontier Foundation, American Civil Liberties Union, and the American Civil Liberties Union of the Nation's Capital in Support of the Respondents, p. 28, https://apps.fcc.gov/edocs public/attachmatch/DOC-335407A1.pdf.

${ }_{23}^{3}$ FCC, 2018 Restoring Internet Freedom Order, par. 117, p. 70.

${ }^{24}$ Idem, par. 140, p. 84.

${ }^{25}$ Idem, par. 142, p. 86. 
that the protection the 2018 order affords to freedom from Internet-traffic discrimination falls below the minimum threshold required in order for it to be consistent with the open Internet.

If the 2018 order clearly does not construe the Internet-traffic nondiscrimination principle as an open Internet principle, we can just as easily see how it does construe the principle, namely, as a free Internet principle.

For all the differences between the 2015 and 2018 orders, one thing they do have in common: neither construes the nondiscrimination principle as an open Internet principle.

If nothing else, the 2018 order delivers in its substance what it advertises in its title: it can in this sense claim a forthrightness that cannot be claimed by the 2015 order it supersedes.

\section{The protection of freedom from Internet traffic discrimination in the 2018 Restoring Internet}

\section{Freedom Order}

In the 2018 Restoring Internet Freedom Order, the protection of freedom from Internet-traffic discrimination turns on two prohibitions: that against anticompetitive discriminatory practices and that against discrimination violating consumer rights.

If a broadband (Internet service) provider engages in anti-competitive discrimination, it will be in violation of the first prohibition.

Under the 2018 order's Transparency Rule, broadband providers (ISPs) are required to disclose their management practices to the public and the FCC. This applies, in particular, to blocking, throttling, affiliated prioritization, paid prioritization, net congestion, application-specific behaviour, device attachment-rules, and security. ${ }^{26}$

If an ISP engages in practices that differ from those specified in its public disclosure, it will be in violation of the second prohibition.

But what if an ISP engages in a publicly disclosed discriminatory practice that is not anticompetitive and yet harms a legally protected interest? Who or what will protect this interest?

The 2018 order could not be clearer in its answer to this question: the market.

As an example of a protected interest, the FCC cites freedom of expression, reassuringly predicting that «market competition [...] will protect values such as free expression, to the extent that consumers value free expression as a service attribute and are aware of how their ISPs' actions affect free expression». ${ }^{27}$ In that example, what the market protects is the freedom of consumers to switch to a different ISP if their current ISP engages in discriminatory practices that violate freedom of expression: freedom of expression

\footnotetext{
${ }^{26} \mathrm{Idem}$, par. 220, p. 130.

${ }^{27}$ Idem, par. 153, p. 93.
} 
becomes a «service attribute», and if end users value it as such, then the market will protect it by enabling them to switch to an ISP that in their view is not violating that «value» or is otherwise delivering a «value» that they want as a «service».

But there is a very real possibility that in discriminating among types or sources of Internet traffic, an ISP may harm an interest worthy of protection other than the interest in a properly functioning market. A broadband provider could, for example, block the website of a hostile trade union or an online service for publishing information that goes against its editorial policy, or even the URL of this study. ${ }^{28}$ In these examples, the interests that warrant legal protection are, respectively, the freedom of trade unions to collectively bargain, freedom of expression, and the freedom to carry out independent research.

ISPs may also demand payment of a fee for access to their customers, as well as block or slow down the applications of edge providers who cannot or do not want to pay such a fee. To be sure, if the fee reflects market prices and is charged to all edge providers without distinction, blocking or slowing down cannot be deemed anticompetitive. But even if the fee is in line with market prices or is cost-oriented, it may not be affordable for a small and promising start-up that has developed what might become the killer app of the next decade: the fee could swallow the start-up's limited financial resources, thus preventing or at least hindering research and development. At stake in this last example is an interest in making sure that the Internet can expand as far and as fast as possible, which according to a well-known and widely shared view depends to a large extent on the speed of innovation in online applications.

Against all these forms of discrimination the 2018 order protects the freedom of consumers to change their broadband provider. It is clear, however, that in order for this protection to be effective it needs to satisfy two conditions: for one thing, consumers need to have the ability to say that the behaviour of their broadband provider is discriminatory; and, for another, there needs to be at least one competing broadband provider. Even if we concede, for the sake of argument, that the first condition is met under the Transparency Rule contained in the 2018 order, the same cannot be said of the second condition. For, as we will see shortly, there are broad swaths of the population, at least in the United States, where consumers do not have the option of switching to a competing ISP.

\footnotetext{
${ }^{28}$ Two of the examples just mentioned have actually happened and are therefore far from hypothetical: in 2005 Telus, the leading telecommunications company in western Canada, blocked two sites related to a labour dispute with the Telecommunications Workers Union, and in 2007 Verizon Wireless rejected a request from Naral ProChoice America, an abortion rights group, to make Verizon's mobile network available for a text-messaging program.
} 


\subsection{The ineffective protection afforded under the 2018 order}

According to data published by the FCC in the 2016 Broadband Progress Report, «approximately 51 percent of Americans have one option for a provider of 25 Mbps/ 3 Mbps fixed broadband service [these being the minimum download and upload speeds set by the FCC for broadband] [...]. Americans in urban areas have significantly more providers offering $25 \mathrm{Mbps} / 3 \mathrm{Mbps}$ speeds than Americans in rural areas. In rural areas, only 13 percent of Americans have more than 1 option for service compared to 44 percent in urban areas» (italics added). ${ }^{29}$ What emerges from this dataset is that the majority of Americans lack the only tool that under the 2018 order they have at their disposal if they should want to punish a fixed broadband service provider for a discriminatory practice that is neither undisclosed nor anticompetitive.

It could be pointed out that «approximately 89 percent of the US population lived in census blocks with LTE coverage by at least four service providers». ${ }^{30}$ However, the current Republican-led FCC has taken the position, repeatedly expressed in the past by the FCC under a Democratic majority, that fixed and mobile broadband services are not functionally the same. ${ }^{31}$

Finally, the condition of the minority of the population that does have an alternative to its current broadband provider is only seemingly better. Indeed, the alternative is more theoretical than practical, considering that end users deciding to switch to a different broadband provider can incur substantial costs. $^{32}$

\section{What might explain the FCC's policymaking, and why it is ill-suited to the North American BIAS market}

A policy under which to regulate any area of activity cannot be appropriate if it disregards the context to which it applies. And the context of the FCC's broadband policy is marked by two salient features. The first of these is an economic feature, consisting in the scarcity of competition in the Broadband Internet Access Service (BIAS) market. The second one has to do with the current state of information

\footnotetext{
${ }^{29}$ FCC, 2016 Broadband Progress Report, par. 86, p. 38.

${ }^{30}$ FCC, Mobile Wireless Competition Report (20th Annual), par. 77, p. 55.

${ }^{31}$ FCC, 2018 Broadband Deployment Report, par. 18, p. 7: «we disagree with those that argue that mobile services are currently full substitutes for fixed service. Both fixed and mobile services can enable access to "information, entertainment, [and] employment options," but there are salient differences between the two technologies. Beyond the most obvious distinction that mobile services permit their users mobility, there are clear variations in consumer preferences and demands for fixed and mobile services». As mentioned in the text, the same opinion was expressed by the previous FCC under Democratic leadership. See FCC, 2016 Broadband Progress Report, par. 12, p. 7: «fixed and mobile broadband are not functional substitutes». And FCC, 2015 Broadband Progress Report and Notice of Inquiry on Immediate Action to Accelerate Deployment, par. 11, p. 6: «fixed and mobile broadband might be complementary, rather than substitutes».

32 A. D. MELAMED - A. W. CHANG, What Thinking about Antitrust Law Can Tell Us About Net Neutrality, in Colo. Tech. L.J., 2016, vol. 15, p. 96.
} 
technology, which is not yet at the point where it can enable mobile broadband services to keep pace with the growing demand for bandwidth. Both of these features need to be taken into account in framing a policy by which to regulate any discriminatory treatment of Internet traffic.

The net neutrality policy clearly fails in this respect. For in its approach to the principle of nondiscrimination in the management of Internet traffic it proceeds from the ideological premise that all discrimination in this area is inherently harmful, regardless of its effects. The policy is thus not contextsensitive but is rather context-independent.

The free Internet policy, for its part, can also be described as ideological in the sense that it proceeds from a free-market approach to the problem of discrimination in the management of Internet traffic. It is not, however, ideological in the absolutist, uncompromising sense that net neutrality is. For in recognizing Internet-traffic discrimination as a problem to be dealt with it also recognizes that the market has an effective role to play in protecting the right of consumers to be free from such discrimination. In the FCC's hands, however, the free Internet relapses into absolutist ideology, for under the 2018 order it fails to take into account the specific context of its application in the North American BIAS market, and particularly the scarce and even inexistent competition in that market.

For this reason, it is rather an open internet policy that the FCC should have embraced. As discussed, the open Internet is an approach at once pragmatic and rational, such that, in construing the Internettraffic nondiscrimination principle, it looks at the context in which this principle is to apply, and specifically at the economic features of this context (to wit, its lack of significant competition) and its technological features (the state of its IT engineering).

None of this pragmatic context-sensitivity can be found in either the 2015 or the 2018 FCC order, both of which accordingly lie outside the open Internet framework. Indeed, as we saw, the 2015 orderdespite a title that sets us up to expect an open Internet policy-actually protects net neutrality, while the 2018 order shoehorns a free Internet policy into a market that happens to lacks the competition one might expect to find in a free market.

We can see, then, that the FCC's 2015 net neutrality policy and its 2018 free Internet policy are both ideological in the context-independent sense just illustrated. And I would argue that this striking aspect of them can be explained in large part by pointing to regulatory capture, in that both appear to reflect the work of an agency captured by the industry it is meant to regulate.

The 2015 policy was enacted during a wave of «tech populism», ${ }^{33}$ on top of which came the pressure of large edge providers (Google, Netflix, eBay, Facebook, Amazon, Twitter, Microsoft, etc.) and the White

\footnotetext{
${ }^{33}$ R. D. ATKINSON - D. CASTRO - A. MCQUINN, How Tech Populism Is Undermining Innovation, in The Information Technology \& Innovation Foundation, 2015, p.
} 
House: in a move that encroached on the FCC's independence, ${ }^{34}$ President Obama urged the FCC to take up «the strongest possible rules to protect net neutrality» ${ }^{35}$.

The 2018 policy, for its part, was enacted under the pressure exerted by the main broadband providers: significant financial resources were deployed by Verizon, Comcast, AT\&T, and the Internet \& Television Association (NCTA) to have the 2015 order repealed. ${ }^{36}$ There was also the distorting effect owed to an onslaught of fraudulent comments favourable to the repeal of the 2015 order. ${ }^{37}$ And last, but not least, came the change in leadership at the FCC with the election of Donald Trump to the White House.

So, as much as the neutrality of the Internet may be a technical problem, the solutions found for it at the FCC are anything but neutral. For, as is perhaps inevitable, the policies through which the agency has construed the principle of nondiscrimination in the management of Internet traffic appear to owe their shape to the conditioning of populist, political, and economic forces.

\section{Conclusion}

In this study we have looked at three policies under which the principle of nondiscrimination in the management of Internet traffic has been construed and applied: net neutrality, the free Internet, and the open Internet. Net neutrality, we have found, informs the FCC's 2015 Open Internet Order, and the free Internet its 2018 Restoring Internet Freedom Order.

https://ssrn.com/abstract=3066771 or http://dx.doi.org/10.2139/ssrn.3066771: «the ongoing net neutrality debate undoubtedly represents one of the clearest examples of tech policy gone awry due to populist pressure», $\mathrm{p}$. 4.

Nearly 4 million Americans and dozen associations for the protection of online rights exercised their right to comment on the proposed rules. The online public debate that unfolded in the run-up to the 2015 order is analysed in R. FARIS - H. ROBERTS - B. ETLING - D. OTHMAN - Y. BENKLER, Score Another One for the Internet? The Role of the Networked Public Sphere in the U.S. Net Neutrality Policy Debate, in The Berkman Center for Internet \& Society Research Publication Series, $2015, \quad$ p. https://cyber.law.harvard.edu/sites/cyber.law.harvard.edu/files/2015 0210 Score Another One. The authors highlight in particular that «unlike earlier instances of successful online mobilization, which focused on the easier task of stopping a proposed action in a veto-rich environment, the net neutrality debate is the first major example of a successful campaign to achieve an affirmative rule change in the teeth of well-organized lobbying opposition». ${ }^{34}$ Regulating The Internet: How The White House Bowled Over FCC Independence, A Majority Staff Report of the Committee on Homeland Security and Governmental Affairs United States Senate, https://www.hsgac.senate.gov/media/majoritymedia/chairman-johnson-releases-report-on-how-the-white-house-bowled-over-fcc-independence.

35 President Obama's Statement on Net neutrality, http://www.whitehouse.gov/net-neutrality\#section-read-thepresidents-statement

${ }^{36}$ According to MapLight, «three of the largest internet service providers and their trade association have spent at least $\$ 26.3$ million on lobbying the federal government since April 1 -about $\$ 1.12$ for every public comment filed with the government on a repeal of net neutrality rules», https://maplight.org/story/as-millions-of-americansspent-time-commenting-on-net-neutrality-internet-providers-spent-1-12-for-each-comment/.

${ }_{37}$ Dissenting Statement of Commissioner Jessica Rosenworcel, p. 2: «two million comments feature stolen identities. Half a million comments are from Russian addresses. Fifty thousand consumer complaints are inexplicably missing from the record». 
That is what an analysis of the two orders reveals. What a critical assessment of them suggests is that their underlying policies, while reasonable in the abstract, fail to take into account the characteristics of the context in which they are meant to be implemented, and in particular they disregard the uncompetitive nature of the North American BIAS market and the state of IT technology in that market. So the question comes up: if the FCC has crafted policies without paying attention to the needs of the sector is it tasked with regulating, what has the agency paid attention to? The answer to that question, I submit, is that the FCC has yielded to the pressures of industry, populism, politics, and the economy. If the FCC had acted as a truly independent body, as any regulatory agency should, it would have enacted a policy that is heedful of the characteristics that shape the current North American BIAS market, namely, an open Internet policy. 